\title{
Thermoregulatory responses to hyperinsulinaemic hypoglycaemia and euglycaemia in IDDM
}

\author{
D. G. Maggs ${ }^{1}$, I. A. Macdonald ${ }^{1}$, R. B. Tattersall ${ }^{2}$ \\ ${ }^{1}$ Department of Physiology and Pharmacology, University of Nottingham, Nottingham, UK \\ ${ }^{2}$ Department of Diabetes and Endocrinology, Queens Medical Centre, Nottingham, UK
}

\begin{abstract}
Summary In healthy subjects hypoglycaemia causes a fall in body temperature through increased sweating and limb blood flow, and despite increased metabolic heat production. We studied thermoregulatory responses to hyperinsulinaemic $\left(100 \mathrm{mU} \cdot \mathrm{m}^{-2} \cdot \mathrm{min}^{-1}\right)$ (a) hypoglycaemia $(2.5 \mathrm{mmol} / \mathrm{l})$ and (b) euglycaemia $(4.5 \mathrm{mmol} / \mathrm{l})$ in insulin-dependent diabetic men of short ( $<5$ years) and long ( $>15$ years) diabetes duration. Plasma noradrenaline $(p<0.0001)$, metabolic rate $(p$ $<0.005)$, heart rate $(p<0.0001)$ and skin blood flow $(p<0.05)$ increased during hypoglycaemia and euglycaemia with a greater rise in noradrenaline during the former $(p<0.05)$. Plasma adrenaline $(p<0.005)$, forearm blood flow $(p<0.05)$ and systolic blood
\end{abstract}

pressure $(p<0.02)$ increased and diastolic blood pressure decreased $(p<0.005)$ during hypoglycaemia, with greater changes in adrenaline $(p<0.05)$ and diastolic blood pressure in patients of short diabetes duration. Only two patients (diabetes duration $<2$ years) sweated appropriately, while body temperature changed minimally in the two groups of patients. In summary, thermoregulatory responses to hypoglycaemia are impaired in IDDM due to attenuated sweating and adrenomedullary responses. [Diabetologia (1994) 37: 689-696]

Key words Blood glucose, body temperature, diabetes mellitus insulin.
In healthy subjects hypoglycaemia causes a disturbance of thermoregulation: heat is dissipated and core temperature falls despite an increase in heat production [1]. Heat dissipation occurs primarily through sympathetically mediated sweat production and subsequent evaporative heat loss but also by increased peripheral blood flow. The rise in heat production is caused by increased sympathoadrenal activity and limb muscle blood flow increases through the effects of increased plasma adrenaline. It is thought that skin blood

Received: 22 October 1993

and in revised form: 12 January 1994

Corresponding author: Dr. I.A.Macdonald, Department of Physiology and Pharmacology, Faculty of Medicine, University of Nottingham, Medical School, Queen's Medical Centre, Nottingham NG7 2UH, UK

Abbreviations: IDDM, Insulin-dependent diabetes mellitus; ANOVA, analysis of variance; BMI, body mass index. flow increases through withdrawal of vasoconstrictor tone [2] which is at odds with the often reported skin pallor noted in hypoglycaemic subjects.

Hypothermia is known to accompany hypoglycaemia in diabetic patients [3] but there is little detailed information of the associated thermoregulatory changes. There are several potential areas where responses in diabetic patients may differ from those of normal subjects: the sympathoadrenal response to hypoglycaemia is attenuated in diabetes of long duration [4], diabetic patients have abnormal vascular responses to a number of different stresses [5], more specifically, there is evidence that skin vascular responses to hypoglycaemia may be abnormal [6] and abnormal sweating is well documented [7]. We have therefore examined the thermoregulatory responses to sustained hyperinsulinaemic hypoglycaemia and euglycaemia in IDDM of short and long duration in a single blind, experimental protocol. 
Table 1. Age, BMI, diabetes duration, $\mathrm{HbA}_{1}$ and starting glucose of study patients

\begin{tabular}{|c|c|c|c|c|}
\hline & \multicolumn{4}{|l|}{ Diabetes } \\
\hline & \multicolumn{2}{|l|}{ Short duration } & \multicolumn{2}{|l|}{ Long duration } \\
\hline & Mean (SEM) & Range & Mean (SEM) & Range \\
\hline Age (years) & $27.3(1.3)$ & $22-32$ & $25.9(1.4)$ & $22 \cdots 31$ \\
\hline $\mathrm{BMI}\left(\mathrm{kg} / \mathrm{m}^{2}\right)$ & $25.5(1.7)$ & $20.3-31.7$ & $24.0(1.0)$ & $20.0-27.3$ \\
\hline $\mathrm{HbA}_{1}(\%)$ & $8.5(0.7)$ & $6.6-11.6$ & $9.0(0.7)$ & $8.3-12.1$ \\
\hline
\end{tabular}

Values are mean (SEM). Starting glucose is the arterialised venous sample at start of hypoglycaemic clamp

\section{Subjects and methods}

Patients: Fourteen male IDDM patients (Table 1), equally divided into short ( $<5$ years) and long $(>15$ years) diabetes duration, were recruited from the diabetes clinic of University Hospital, Nottingham. All were otherwise healthy and on no additional medication. Three smoked but abstained on study days. All gave written informed consent to the study which was approved by the University Hospital Ethics Committee. All subjects were treated with twice daily isophane and short-acting insulin regimens and they witheld isophane insulin from the previous $24 \mathrm{~h}$ and short-acting insulin on the morning of the study. Subjects fasted from the night before ( 22.00 hours) and on arrival at the hospital ( 08.00 hours) an intravenous catheter was inserted into the antecubital fossa for a low-dose insulin infusion (Human Actrapid; Novo Nordisk, Copenhagen, Denmark), the rate of which was adjusted to maintain blood glucose between 4.5 and $6 \mathrm{mmol} / 1$ for at least $2 \mathrm{~h}$ prior to study at 14.00 hours. A second catheter was inserted retrogradely into the dorsum of the hand for blood sampling and the hand was placed in a heated box $\left(55^{\circ} \mathrm{C}\right)$ to arterialise the venous blood [8]. Studies were performed with the subjects lightly dressed lying supine in thermoneutral conditions $\left(30^{\circ} \mathrm{C}\right)$. Subjects with a history of symptomatic hypoglycaemia during the previous $24 \mathrm{~h}$ or with a documented low blood glucose $(<4 \mathrm{mmol} / \mathrm{l})$ at the time of arrival or during the morning period of stabilisation were excluded from the study.

Protocol: In random order, and with subjects unaware of the nature of the study, the two visits involved: hyperinsulinaemic hypoglycaemia $(\mathrm{H})$, and euglycaemia $(\mathrm{E})$. Using an adaptation of the hyperinsulinaemic clamp [9] we infused insulin $(100 \mathrm{mU}$. $\mathrm{m}^{-2} \cdot \mathrm{min}^{-1}$ ) and glucose (dextrose $20 \%$ [weight/volume]) for $90 \mathrm{~min}$ to maintain blood glucose at either $2.5 \mathrm{mmol} / \mathrm{l}(\mathrm{H})$ or $4.5 \mathrm{mmol} / \mathrm{l}(\mathrm{E})$ for the final $60 \mathrm{~min}$.

Measurements: Arterialised venous blood samples were taken from the retrograde cannula for measurement of blood glucose at 3-5 min invervals. During the baseline period and at 20 -min intervals during the experimental clamp further blood was taken for measurement of noradrenaline and arenaline by high performance liquid chromatography [10]. Metabolic rate was measured by indirect calorimetry during baseline and the 60 -min clamp [11]. All other measurements were made at 10 -min intervals during the baseline and $90-\mathrm{min}$ infusion. Core temperature was measured by an aural thermistor in the external auditory canal. Skin temperature was measured by surface thermocouples at the forehead, abdomen, calf, shin and dorsum of the foot. Sweat evaporation rate was measured by a dew point sensor connected to a ventilated capsule on the anterior abdominal wall (Michell Instruments Ltd., Series 2000, Cambridge, UK).
Right forearm and right great toe blood flow were measured by mercury-in-silastic strain gauge venous occlusion plethysmography [12]. Skin blood flow was measured at two sites (left toe pulp and dorsum of the left foot) by laser Doppler flowmetry (MBF2; Moor Instruments, Opto-electronic Instrumentation, Axminster, UK). Heart rate was reorded from an electrocardiogram and brachial arterial blood pressure measured by auscultation using a mercury sphygmomanometer.

At a further visit all patients underwent cardiac autonomic function testing [13] and an acetylcholine sweat spot test [14] with concurrent blood glucose above $4.5 \mathrm{mmol} / \mathrm{l}$. Testing and analysis of these results were performed by an independent observer blinded to specific patient details.

\section{Statistical analysis}

Results were analysed by three-way ANOVA with repeated measures using the statistical package BMDP (BMDP statistics software, Los Angeles, Calif., USA). Time effects represent changes from baseline during the study. Treatment effects (treatment/time interaction) represent a difference in response between the two visits ( $\mathrm{E}$ and $\mathrm{H})$. Duration effects represent a difference in responses between patients of short and long diabetes duration. Unless otherwise stated ANOVA statistics are presented as a treatment/ime interaction between the two visits. Data were sphericity tested to determine normal distribution. Non-normal data was corrected by Huynd-Feldt factor. The levels of significance at individual time points were calculated by paired $t$-tests, using the variance term for the interaction from ANOVA and a Bonnferroni correction applied for multiple testing. Statistics are presented as $F$-ratio and probability (ANOVA). Results in text are expressed as mean and SEM with the exception of sweating responses where individual responses are plotted. For the sake of clarity, data are presented graphically as changes from baseline with the exception of blood glucose and sweating responses which are presented as absolute values. Metabolic rate and catecholamine data are presented for the clamp period only ( 0 to $60 \mathrm{~min}$ ), whereas, the remaining data are presented for the entire 90 -min infusion period $(-30$ to $60 \mathrm{~min}$ ). Where significant differences in responses exist between patients of short and long diabetes duration, data are presented separately for these groups.

\section{Results}

Autonomic function: All patients of short diabetes duration had normal autonomic function. Two of long diabetes duration had abnormal results; one with evidence of cardiac autonomic neuropathy the 
Table 2. Autonomic function test results

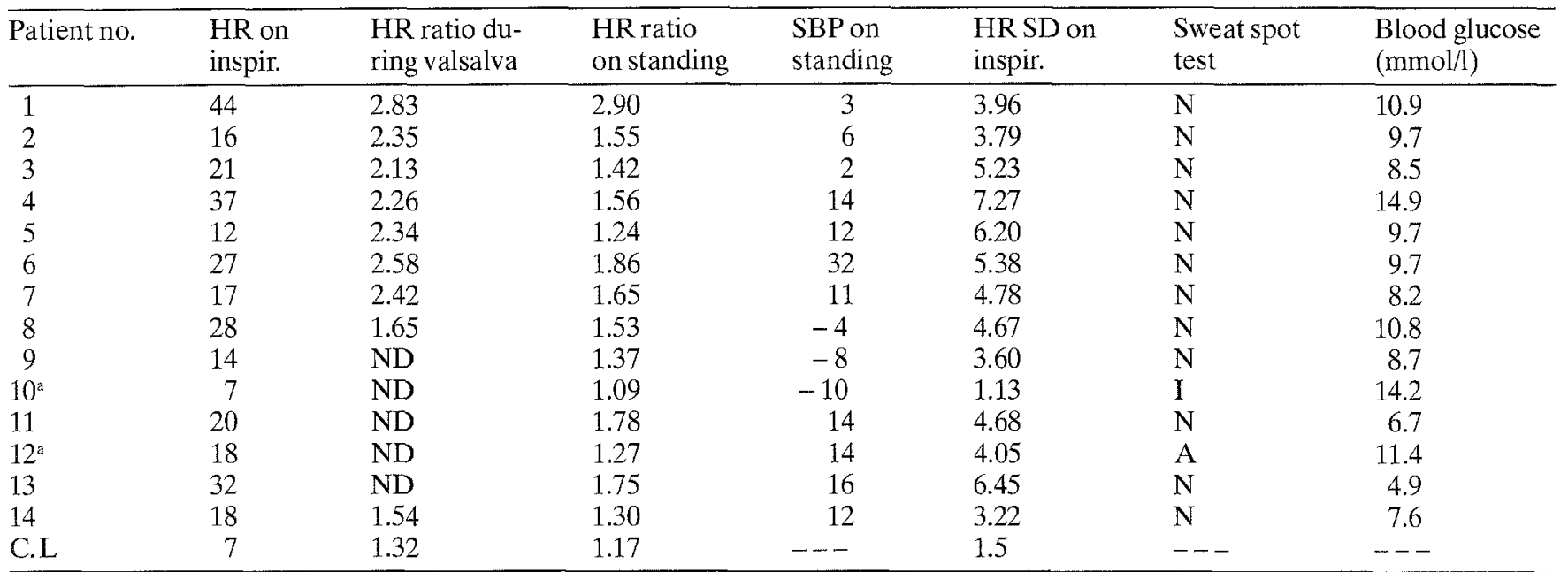

HR, Heart rate; Inspir, inspiration; SBP, systolic blood pressure; SD, standard deviation; ND, not done; N, normal; I, impaired; A, abnormal; Patients 1 to 7 , short duration diabetes; 8 to 14 ,

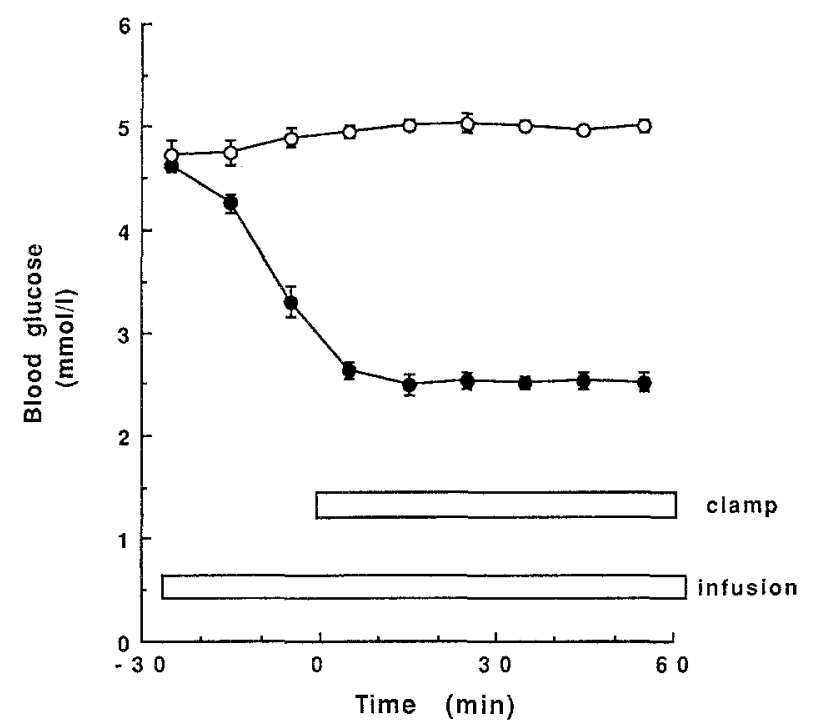

Fig. 1. Arterialised venous blood glucose during hypoglycaemia (0) and euglycaemia (O). Values are plotted from the start of insulin infusion ( $-30 \mathrm{~min}$ ) to the end of the 60 -min clamp and are mean with SEM expressed as vertical bars

other with an attenuated sweat spot test response (Table 2).

Thermoregulation: Thermoneutral conditions were sustained throughout the study and baseline data did not differ between hypoglycaemic and euglycaemic study visits. Target blood glucose levels were achieved during hypoglycaemia and euglycaemia (Fig. 1). Baseline metabolic rate was $5.5 \pm 0.2 \mathrm{~kJ} / \mathrm{min}$ before euglycaemia and $5.2 \pm 0.2$ before hypoglycaemia (NS). Metabolic rate increased with time during both hypoglycaemia and euglycaemia (time effect: $F$ 8.8; $p<$ $0.005)$ with a trend to a greater rise during hypoglycaemia ( $F$ 2.18; $p=0.08$ ) (Fig. 2). There was also a trend to a greater increase in metabolic rate above long duration diabetes. C.L., $95 \%$ confidence limits of age-corrected normal range. ${ }^{\mathrm{a}}$ Abnormal autonomic function

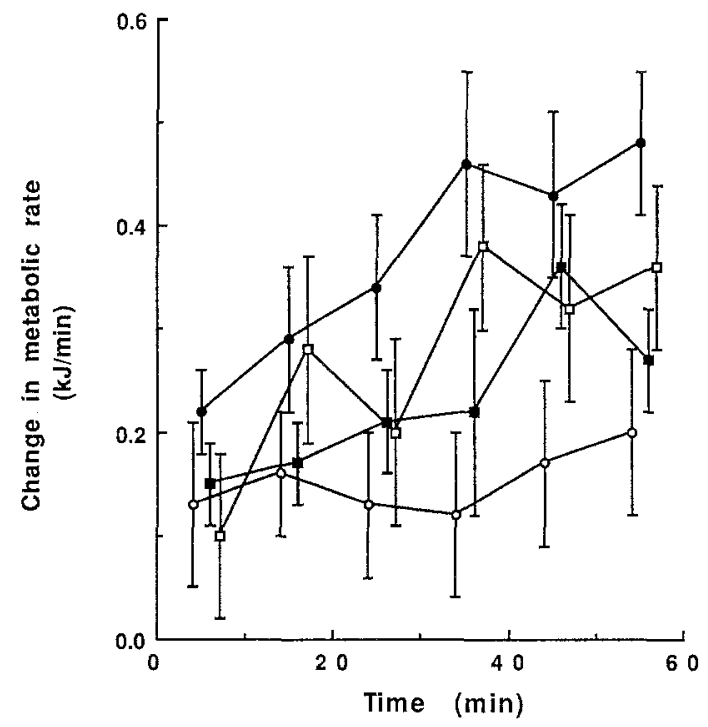

Fig.2. Change in metabolic rate from baseline during hypoglyca-

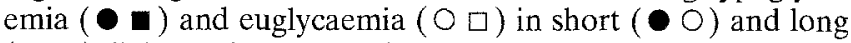
( $\square$ - ) diabetes duration patients. Values are plotted during the 60-min clamp and are mean with SEM expressed as vertical bars

baseline during hypoglycaemia in short diabetes duration patients ( time/treatment/duration effect $F 2.45 ; p=$ 0.07) (Fig. 2).

Sweating varied widely during hypoglycaemia (Fig.3) and two patients with a diabetes duration less than 2 years had the greatest sweating response. Overall sweating increased with time with no significant difference between hypoglycaemic and euglycaemic visits. During hypoglycaemia there was a trend to a fall in core temperature $(F 2.99 ; p=0.06)$ with a negative correlation between individual peak sweating responses and maximal core temperature change (Fig. 4). Skin temperature did not change during hypoglycaemia and euglycaemia, and body temperature responses did not differ between short and long duration groups. 

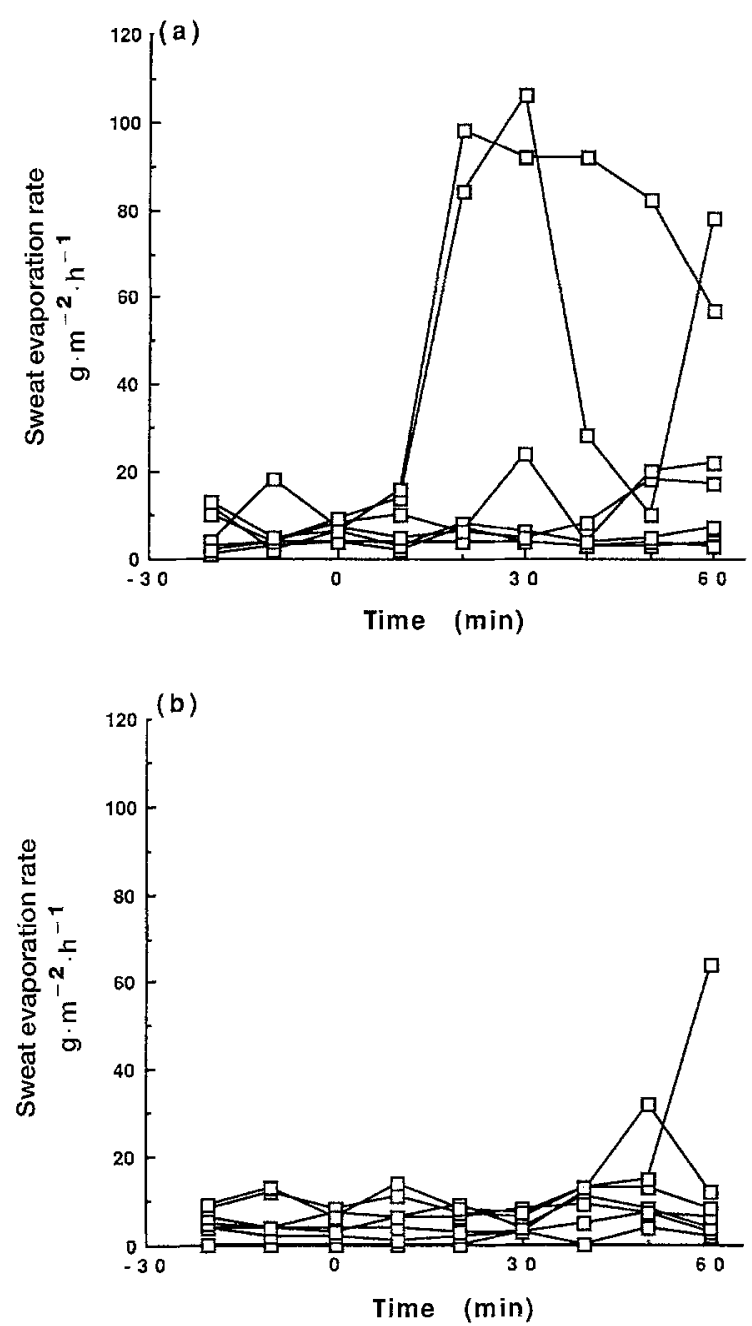

Fig. 3.a,b Individual sweating responses during hypoglycaemia in (a) short and (b) long diabetes duration patients. Values are plotted from the start of insulin infusion ( $-30 \mathrm{~min}$ ) to the end of the 60 -min clamp

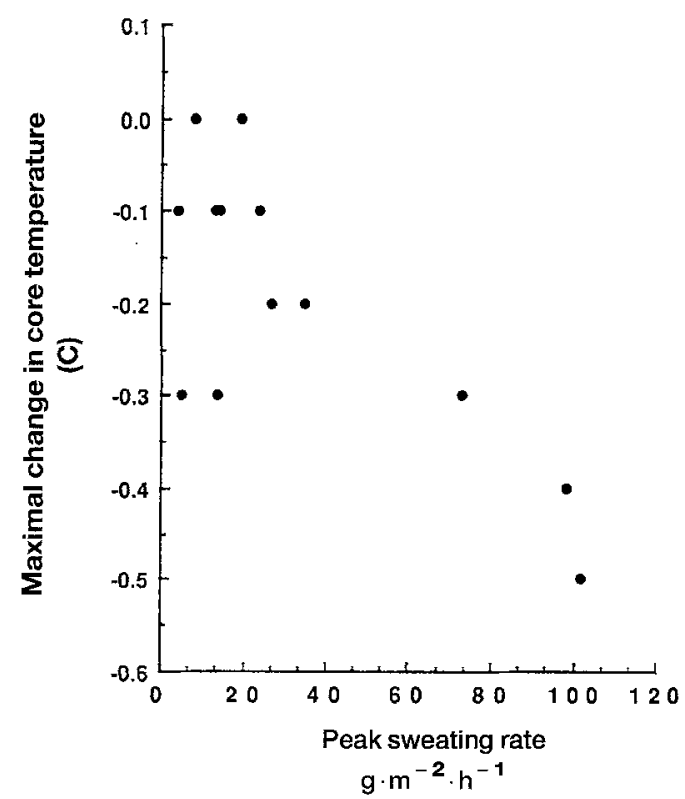

Fig. 4. Plot of individual peak sweating response and maximal core temperature change during hypoglycaemia

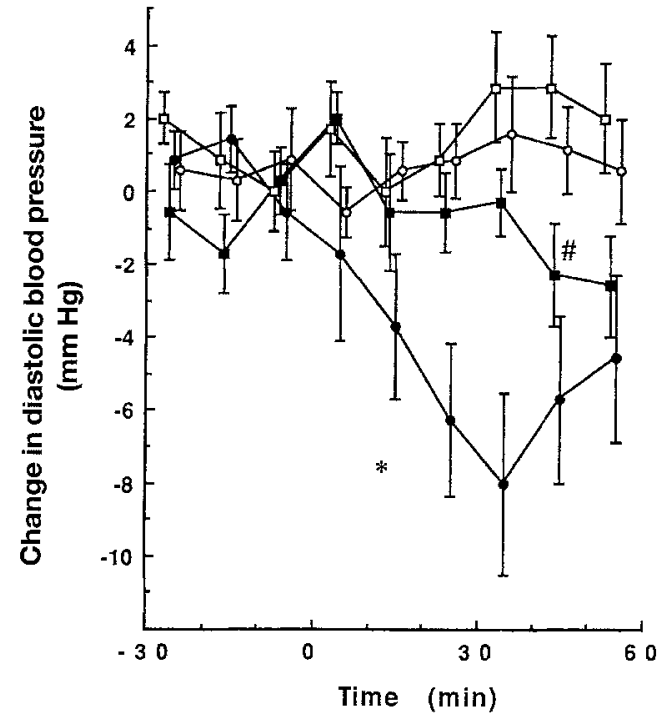

Fig.5. Change in diastolic blood pressure from baseline during hypoglycaemia ( $\square)$ and euglycaemia $(O \square)$ in short $(\bullet \circ)$ and long diabetes duration ( $\square$ ) patients. Values are plotted from the start of insulin infusion $(-30 \mathrm{~min})$ to the end of the 60-min clamp and are mean with SEM expressed as vertical bars * First significant change during hypoglycaemia compared with euglycaemia in short diabetes duration patients $(p<0.01)$. \# First significant change during hypoglycaemia compared with euglycaemia in long diabetes duration patients $(p<0.01)$

Cardiovascular responses: Baseline values were not significantly different before the hypoglycaemic and euglycaemic clamps (Table 3 ). There were some differences between the patients with diabetes of short and long duration, notably for forearm blood flow, toe blood flow and dorsal foot skin blood velocity (Table 4). Diastolic blood pressure fell during hypoglycaemia $(F 5.23 ; p<0.005)$ with a greater decrease in short diabetes duration patients (time/treatment/duration effect $F 2.87 ; p<0.05$ ) (Fig. 5). Systolic blood pressure increased $(F 3.28 ; p<0.02)$ with no difference between short and long diabetes duration patients (Fig.6a). Blood pressure did not change during euglycaemia. Heart rate increased during hypoglycaemia and euglycaemia (time effect: $F 8.26 ; p$ $<0.0001$ ) with no difference in response between short and long diabetes duration patients (Fig. 6b) and a trend to a greater increment during hypoglycaemia ( $F 2.42 ; p=0.08)$.

Forearm blood flow (Fig. 7) increased during hypoglycaemia $(F 6.9 ; p<0.05)$, with a trend to a greater increment in short diabetes duration patients (time/treatment/duration effect $F 4.2 ; p=0.06$ ). Euglycaemia did not affect forearm blood flow. During hypoglycaemia and euglycaemia skin blood velocity of the dorsum of the foot increased (time effect: $F 7.04 ; p<0.002$ ) and toe blood flow did not change. Skin blood velocity of the toe pulp increased during euglycaemia ( $F 2.98$; $p<0.05)$ with a trend to a fall during hypoglycaemia $(F 2.43 ; p=0.06)$. 
Table 3. Baseline cardiovascular variables before hypoglycaemic and euglycaemic visits

\begin{tabular}{lcccc}
\hline & Hypoglycaemia & Euglycaemia & $F$ value & $p$ value \\
\hline Systolic BP $(\mathrm{mm} \mathrm{Hg})$ & $118(3)$ & $117(2)$ & 0.07 & 0.80 \\
Diastolic BP $(\mathrm{mm} \mathrm{Hg})$ & $77(2)$ & $78(1)$ & 0.01 & 0.93 \\
Heart rate $\left(\mathrm{min}^{-1}\right)$ & $71(2)$ & $70(3)$ & 0.30 & 0.59 \\
FBF $\left(\mathrm{ml} \cdot \mathrm{min}^{-1} \cdot 100 \mathrm{ml}^{-1}\right)$ & $4.2(0.9)$ & $4.4(0.9)$ & 0.42 & 0.56 \\
TBF $\left(\mathrm{ml} \cdot \mathrm{min}^{-1} \cdot 100 \mathrm{ml}^{-1}\right)$ & $8.2(1.2)$ & $0.2(1.9)$ & $0.39(0.10)$ & 0.96 \\
Toe pulp SBV (volts) & $0.60(0.11)$ & $0.12(0.02)$ & 0.47 & 0.50 \\
Foot SBV (volts) & $0.12(0.02)$ & & & 0.39 \\
\hline
\end{tabular}

Results presented as mean (SEM)

$\mathrm{BP}$, Blood pressure; FBF, forearm blood flow; TBF, toe blood flow; SBV, skin blood velocity; $F$ value, ANOVA statistic; $p$ value, significance

Table 4. Baseline blood pressure, heart rate and peripheral blood flow values in patients of short and long diabetes duration

\begin{tabular}{|c|c|c|c|c|}
\hline \multirow[b]{2}{*}{ Measurement } & \multirow{2}{*}{$\frac{\text { Short }}{\text { Mean (SEM) }}$} & \multicolumn{3}{|l|}{ Long } \\
\hline & & Mean (SEM) & fvalue & $p$ value \\
\hline Systolic BP (mmHg) & $114(5)$ & $120(7)$ & 1.20 & 0.49 \\
\hline Heart rate $\left(\min ^{-1}\right)$ & $66(7)$ & $75(6)$ & 1.81 & 0.24 \\
\hline $\mathrm{FBF}\left(\mathrm{ml} \cdot \mathrm{min}^{-1} \cdot 100 \mathrm{ml}^{-1}\right)$ & $4.89(0.61)$ & $3.65(0.18)$ & 2.59 & $<0.05$ \\
\hline $\mathrm{TBF}\left(\mathrm{ml} \cdot \mathrm{min}^{-1} \cdot 100 \mathrm{ml}^{-1}\right)$ & $10.63(1.21)$ & $5.77(1.16)$ & 3.89 & $<0.01$ \\
\hline
\end{tabular}

Values presented are the means of the two baseline periods. BP, Blood pressure; FBF, forearm blood flow; TBF, toe blood

Catecholamine responses: Baseline values of plasma catecholamines did not differ before the euglycaemic (noradrenaline, $\quad 1.20 \pm 0.11$, adrenaline $0.42 \pm$ $0.06 \mathrm{nmol} / \mathrm{l}$ ) and hypoglycaemic (noradrenaline, 1.13 \pm 0.12 , adrenaline $0.48 \pm 0.07 \mathrm{nmol} / \mathrm{l}$ ) clamps. Plasma adrenaline (Fig. $8 \mathrm{a}$ ) increased after $20 \mathrm{~min}$ of hypoglycaemia $(F 13.4 ; p<0.005)$ with a greater increase in patients of short diabetes duration (time/treatment/duration effect $F 3.05 ; p<0.05)$. Plasma noradrenaline (Fig. 8 b) increased during hypoglycaemia and euglycaemia (time effect: $F 11.35 ; p<0.0001$ ) with a greater increment during hypoglycaemia $(F 2.48 ; p<$ 0.05 ). There was a trend to a greater rise in plasma flow; SBV, skin blood velocity; $F$ value, ANOVA statistic; $P$ value, significance

noradrenaline during both hypoglycaemia and euglycaemia in short diabetes duration patients (time/duration effect $F 2.79 ; p=0.08$ ).

\section{Discussion}

This study demonstrates abnormal thermoregulatory responses to hypoglycaemia in IDDM patients. Increases in metabolic heat production and plasma adrenaline varied widely between individuals with blunted responses in long diabetes duration patients. An attenuated adrenomedullary response to hypoglycaemia
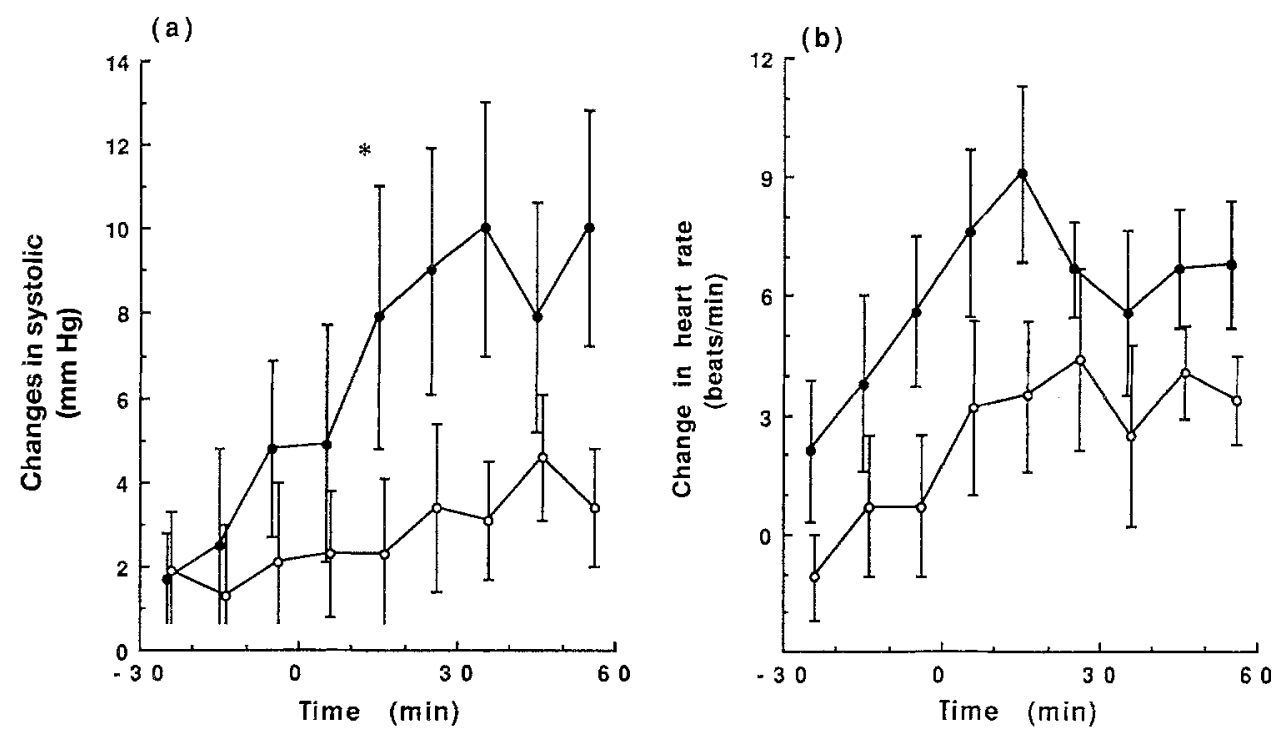

Fig. 6a,b. Change from baseline of (a) systolic blood pressure (SBP) and (b) heart rate during hypoglycaemia $(\bullet)$ and euglycaemia ( $O$ ). There were no differences between patients with short and long diabetes duration. Values are plotted from the start of insulin infusion ( $-30 \mathrm{~min}$ ) to the end of the 60 -min clamp and are mean with SEM expressed as vertical bars * First significant difference between hypoglycaemia and euglycaemia $(p<0.05)$ 


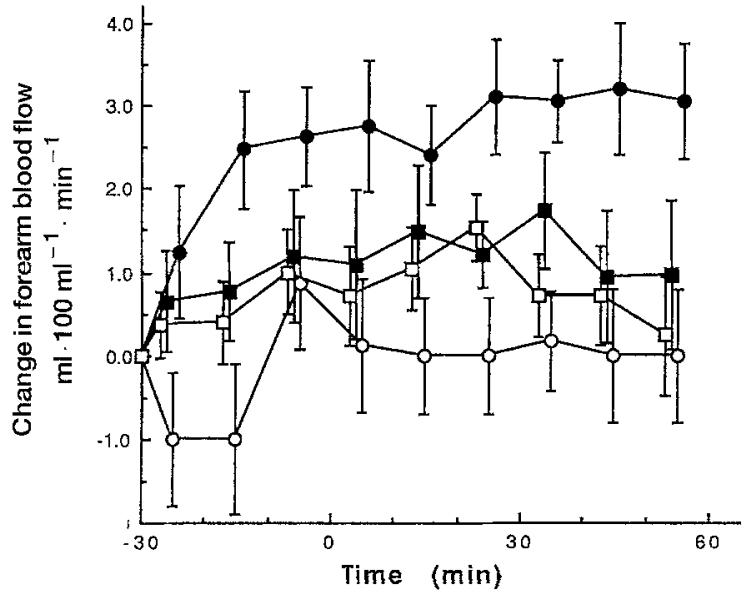

Fig. 7. Change from baseline of forearm blood flow during hypoglycaemia $(\square)$ and euglycaemia $(O \square)$ in short $(O)$ and long ( $\square$ ) diabetes duration patients. Values are plotted from the start of insulin infusion $(-30 \mathrm{~min})$ to the end of the 60 -min clamp and are mean with SEM expressed as vertical bars

in IDDM patients is well described [4] and is thought to have a multifactorial aetiology [15]. In the past, autonomic neuropathy was implicated as a cause [16], but in this study only one patient of long diabetes duration had cardiovascular evidence of autonomic dysfunction. Antecedent diabetes control influences the adrenomedullary response to hypoglycaemia as near normalisation of blood glucose results in a blunted or absent adrenomedullary response [17] and patients with chronic hyperglycaemia (poor diabetes control) have an adrenomedullary response which occurs at a higher blood glucose level [18]. In this study patients of short and long diabetes duration had comparable measures of antecedent diabetes control $\left(\mathrm{HbA}_{1}\right)$ with a trend to slightly higher levels in long diabetes duration patients, but glycaemic control did not seem to influence the responses. No correlation was noted between $\mathrm{HbA}_{1}$ and the adrenomedullary response although this study was not designed to measure glucose thresholds for adrenaline release. Antecedent hypoglycaemia (within the previous $18 \mathrm{~h}$ ) may also impair the adrenomedullary response to hypoglycaemia in non-diabetic subjects [19] and, as far as we are aware, patients who may have been hypoglycaemic prior to study were excluded. However, the possibility of asymptomatic antecedent hypoglycaemia could not be excluded completely.

Sweating is a common symptom and sign of hypoglycaemia and we have characterised the prompt and sustained nature of the sweating response in a group of healthy males during a hypoglycaemic stimulus identical to that employed in this study, although the plasma insulin levels were approximately $30 \%$ lower [20]. However, only two diabetic patients had a comparable sweating response with the rest having either delayed or negligible responses. Sweating abnor- malities are common in diabetes [7] and are normally seen in the presence of neuropathy [21]. The present patients had no clinical evidence of peripheral neuropathy, all but one had normal acetylcholine sweat spot tests and only one patient had evidence of cardiovascular autonomic dysfunction. This suggests that these
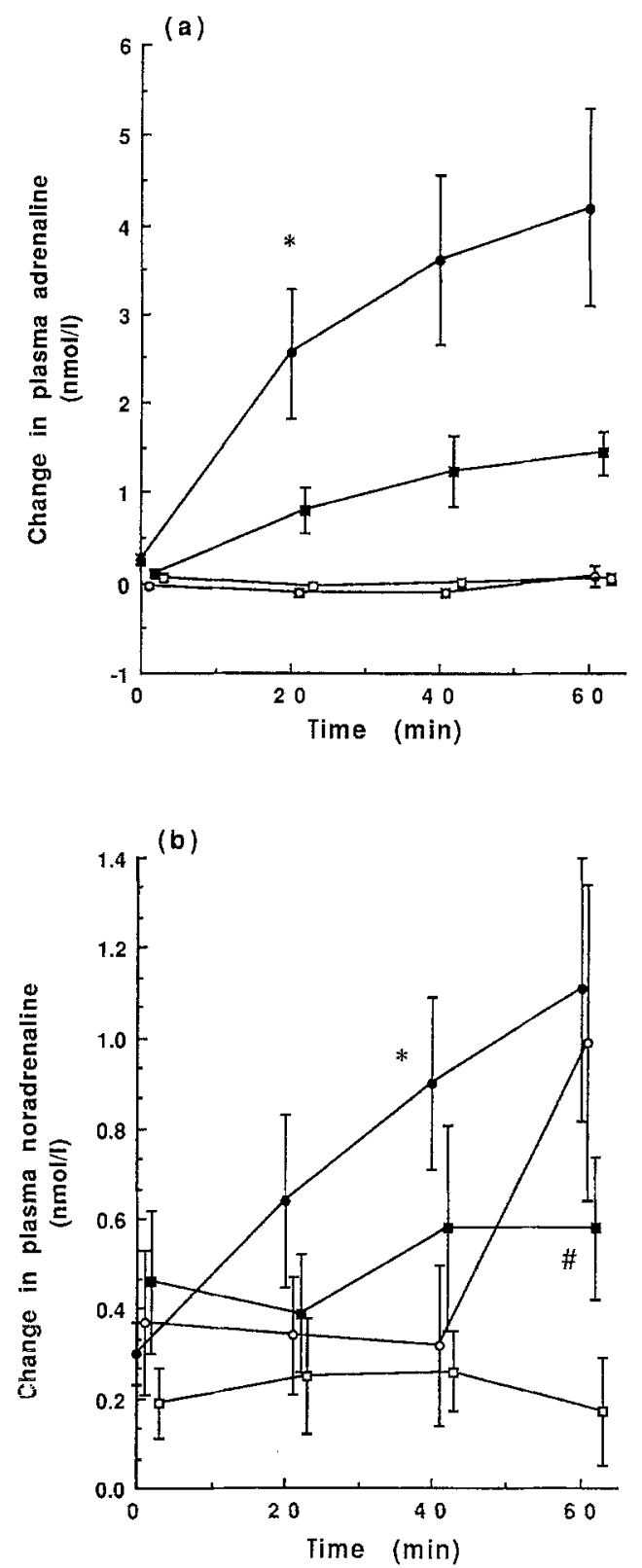

Fig.8 a,b. Change from baseline of plasma (a) adrenaline and (b) noradrenaline during hypoglycaemia ( a) and euglycaemia ( $O \square)$ in short $(\bullet \bigcirc)$ and long $(\square \square)$ diabetes duration patients. Values are plotted during the 60-min clamp and are mean with SEM expressed as vertical bars. (a)* First significant change during hypoglycaemia in short diabetes duration patients compared to their own euglycaemic data, and to hypoglycaemia in long diabetes duration patients $(p<0.001)$. (b) ${ }^{*}$ First significant change during hypoglycaemia in short duration patients compared to their own euglycaemic data $(p<0.01)$. \# First significant change during hypoglycaemia in long diabetes duration patients compared to their own euglycaemic data $(p<0.01)$ 
patients were able to sweat but required a stronger hypoglycaemic stimulus to do so. Diabetes duration may again be an influencing factor as the two patients who had a sweating response similar to that observed in non-diabetic subjects [20] had been diabetic for less than 2 years, a shorter duration than the other patients. As with the adrenomedullary response, glycaemic control did not influence the sweating response to hypoglycaemia. Heat dissipation during hypoglycaemia is caused by evaporative heat loss at the skin surface and is strongly related to the sweating response. Not surprisingly, in these patients body temperature changed very little, both at the skin surface and the core. When sweating did occur core temperature fell. This was demonstrated by a negative correlation between individual sweating responses and core temperature change.

We observed an increase in systolic blood pressure, heart rate and forearm blood flow and a fall in diastolic blood pressure during hypoglycaemia. These changes are mostly caused by increased circulating adrenaline and mediated by beta-adrenoceptors. In long diabetes duration patients the blunted adrenomedullary response was reflected by an attenuated limb vasodilator response and a smaller reduction in diastolic blood pressure. However, heart rate and systolic blood pressure changes were not influenced by diabetes duration. During euglycaemia blood pressure did not change but heart rate increased similarly during hypoglycaemia and euglycaemia. In nondiabetic subjects under similar hyperinsulinaemic euglycaemic conditions increases in heart rate have been reported [22] and are accompanied by evidence of increased sympathetic nervous activity. Metabolic heat production increased during hyperinsulinaemic euglycaemia. This has been described previously in normal subjects [23], and is a manifestation of obligatory and facultative thermogenesis with the latter involving increased sympathetic nervous activity. A trend to a blunted thermic response during hyperinsulinaemic euglycaemia in long diabetes duration patients was associated with lower plasma noradrenaline. This supports the view that under hyperinsulinaemic conditions increased metabolic heat production is, in part, related to increased sympathetic nervous activity.

Past observations of skin blood flow responses to hypoglycaemia have varied. In non-diabetic subjects an early vasodilatory response has been reported [24], whereas in a group of healthy men subjected to sustained hypoglycaemia similar to the present study, we observed vasoconstriction which was most notable in the arteriovenous anastomoses [25]. The former observation was interpreted as a withdrawal of vasoconstrictor tone [2], the latter is probably due to adrenaline mediated alpha-adrenoceptor stimulation. In diabetic patients skin vascular responses are abnormal, which may be explained by the attenuated va- soactive responses to stresses generally [5]. This is highlighted by the observation that the early vasodilator response to hypoglycaemia in the skin of the forehead and forearm of healthy control subjects was absent in diabetic patients [24]. A differential effect of hypoglycaemia on skin blood flow in diabetic patients was reported by Wiles et al. [6] who noted a fall in capillary blood flow but sustained flow in arteriovenous anastomoses. This was interpreted as a thermoregulatory response to dissipate heat in the arteriovenous anastomoses, overriding the effect of high circulating adrenaline. The present patients had an increase in capillary blood flow during hyperinsulinaemic euglycaemia and hypoglycaemia. This may reflect a vasodilatory response to warming in the thermoneutral conditions [26] or a vasodilatory effect of insulin [27]. Blood flow through arteriovenous anastomoses also increased during hypoglycaemia and euglycaemia, with a small and statistically insignificant fall in the later stage of hypoglycaemia. This relative vasoconstrictor response was not as marked as that seen in non-diabetic subjects [25] under identical hypoglycaemic conditions but plasma adrenaline responses were blunted in the diabetic patients.

In summary, we have demonstrated abnormal thermoregulatory responses to hypoglycaemia in IDDM. Diabetic patients showed little change in body temperature and diminished sweating responses. These patients also had abnormal cardiovascular responses to hypoglycaemia which are likely to be partly due to an attenuated adrenomedullary response and may influence thermoregulatory mechanisms. Both the sweating and adrenomedullary responses seem to be influenced by diabetes duration. Animal studies have underlined the importance of hypothermic protection of the central nervous system during hypoglycaemia [28] and there is increasing evidence that repeated hypoglycaemia in IDDM patients may result in loss of cognitive powers [29]. We suggest that during hypoglycaemia IDDM patients of increasing diabetes duration. cannot dissipate heat effectively and are therefore exposed to a greater potential central nervous system insult. The clinical implications of this phenomenon are unknown.

\section{References}

1. Gale E, Bennett T, Green J, Macdonald I (1981) Hypoglycaemia, hypothermia and shivering in man. Clin Sci 61: 463469

2. Berne C, Fagius J (1986) Skin nerve activity during insulininduced hypoglycaemia. Diabetologia 29: 855-860

3. Strauch B, Felig P, Baxter J, Schimpff S (1969) Hypothermia in hypoglycaemia. J Am Med Assoc 210: 345-346

4. Polonsky K, Herold K, Gilden J, et al. (1984) Glucose counterregulation in patients after pancreatectomy. Diabetes 33: 1112-1119

5. Tooke J (1986) Microvascular haemodynamics in diabetes mellitus. Clin Sci 70: 119-125 
6. Wiles P, Grant P, Stickland M, Dean H, Wales J, Davies J (1988) Regional variation in skin blood flow response to hypoglycaemia in type 1 (insulin-dependent) diabetic patients without complications. Diabetologia 31: 98-102

7. Barany F, Cooper E (1956) Pilomotor and sudomotor innervation in diabetes. Clin Sci 15: 533-540

8. McGuire E, Helderman J, Tobin J, Andres R, Bergman R (1976) Effects of arterial versus venous sampling on glucose kinetics in man. J Appl Physiol 41: 65-73

9. De Fronzo R, Jordan D, Tobin, T, Andres R (1979) Glucose clamp technique: a method for quantifying insulin secretion and resistance. Am J Physiol 237: E214-E223

10. Macdonald I, Bennett T, Gale E, Green J, Walford S (1982) The effect of propanolol or metoprolol on thermoregulation during insulin-induced hypoglycaemia in man. Clin Sci 63: 301-310

11. Fellows I, Macdonald I (1985) An automated method for the measurement of oxygen consumption and carbon dioxide excretion in man. Clin Phys Physiol Meas 6: 349-355

12. Whitney R (1953) The measurement of volume changes in human limbs. J Physiol 121: 1-27

13. O'Brien I, O'Hare P, Corrall R (1986) Heart rate variability in healthy subjects: effect of age and the derivation of normal range for tests of autonomic function. Br Heart J 55:348-354

14. Ryder R, Marshall R, Johnson K, Ryder A, Owens D, Hayes $\mathrm{T}$ (1988) Acetylcholine sweatspot test for autonomic denervation. Lancet I: 1303-1305

15. Clarke W, Gonder-Frederick L, Richards F, Cryer P (1991) Multifactorial origin of hypoglycemic symptom unawareness in IDDM. Association with defective counterregulation and better glycemic control. Diabetes 40: 680-685

16. Hilsted J, Madsbad S, Krarup T, et al. (1981) Hormonal, metabolic, and cardiovascular responses to hypoglycaemia in diabetic autonomic neuropathy. Diabetes 30:626-633

17. Simonsen D, Tamborlane W, De Fronzo R, Sherwin R (1985) Intensive insulin therapy reduces counterregulatory hormone responses to hypoglycemia in patients with type 1 diabetes. Ann Int Med 103: 184-190

18. Boyle P, Schwartz N, Shah S, Clutter W, Cryer P (1988) Plasma glucose concentrations at the onset of hypoglycaemic symptoms in patients with poorly controlled diabetes and non diabetics. N Engl J Med 318: 1487-1492

19. Heller S, Cryer P (1991) An antecedent episode of hypoglycaemia reduces neuroendocrine and symptomatic responses to subsequent hypoglycaemia in normal humans. Diabetes 40:223-226

20. Maggs D, Scott A, Macdonald I (1990) Thermogenesis and sweat production during sustained hypoglycaemia in man. Diabetes 39 [Suppl]: 104 (Abstract)

21. Fealey R, Low P, Thomas J (1989) Thermoregulatory sweating abnormalities in diabetes mellitus. Mayo Clin Proc 64: $617-628$

22. Rowe J, Young J, Minaker K, Stevens A, Pallotta J, Landsberg L (1981) Effect of insulin and glucose infusions on sympathetic nervous activity in normal man. Diabetes 30: 219225

23. Gallen I, Macdonald I (1990) Effects of blood glucose concentration on thermogenesis and glucose disposal during hyperinsulinaemia. Clin Sci 79:279-285

24. Aman J, Berne C, Ewald U, Tuvemo T (1990) Lack of cutaneous hyperemia in response to insulin-induced hypoglycemia in IDDM. Diabetes Care 13: 1029-1033

25. Maggs D, Scott A, Macdonald I (1990) Thermoregulation in man; effects of sustained hypoglycaemia. Diabetic Med 7 [Suppl 1]:27 (Abstract)

26. Pickering G, Hess W (1933) Vasodilatation in the hands and feet in response to warming the body. Clin Sci 1: 213-223

27. Tooke J, Lins P, Ostergren J, Adamson U, Fagrell B (1985) The effects of insulin infusion on skin microcirculatory flow in type 1 diabetes. Int J Microcirc Exp 4: 69-83

28. Buchanan T, Cane P, Eng C, Sipos G, Lee C (1991) Hypothermia is critical for survival during prolonged insulin-induced hypoglycemia in rats. Metabolism 40:330-334

29. Langan S, Deary I, Hepburn D, Frier B (1991) Cumulative cognitive impairment following recurrent severe hypoglycaemia in adult patients with insulin-treated diabetes mellitus. Diabetologia 34: 337-344 